AUDIT

\title{
Spontaneous pneumothorax: use of aspiration and outcomes of management by respiratory and general physicians
}

\author{
S Packham, P Jaiswal
}

Postgrad Med J 2003;79:345-347

See end of article for authors' affiliations

Correspondence to:

Dr S Packham, Department

of Respiratory Medicine,

Battle Hospital, Oxford

Road, Reading, Berkshire

RG30 IAG, UK:

Stuart.Packham@

rbbh-tr.nhs.uk

Submitted

6 November 2002

Accepted

14 February 2003

\begin{abstract}
Background: Spontaneous pneumothorax is a common problem in hospital practice. Despite the publication of guidelines controversy over its initial management still exists, particularly over the use of simple aspiration.

Methods: The management of spontaneous pneumothorax by respiratory and general physicians at our hospital was analysed by retrospective case note review. Eighty five patients were identified over the study period ( 36 managed by respiratory and 49 by general physicians).

Results: There was a significantly greater use of simple aspiration by respiratory $(81 \%)$ than general physicians $(47 \%, p<0.001)$ and a higher rate of success in this group. As a result those patients managed by respiratory physicians had fewer intercostal drains inserted and significantly shorter length of stays (mean 5.6 (3.8) days respiratory group and 9.5 (6.8) days in general physicians group, $\mathrm{p}<0.05)$.

Conclusions: The greater and more successful use of simple aspiration by respiratory physicians as an initial treatment for spontaneous pneumothorax resulted in improved outcomes and reduced length of hospital stays.
\end{abstract}

$\mathrm{P}$ rimary spontaneous pneumothorax usually occurs in young patients without pre-existing lung disease. It is a common problem encountered in hospital practice with an incidence of 11 per 100000 per year. Controversy over its management continues to exist despite the publication of guidelines. ${ }^{1-4}$ The aim of this study was to assess the effectiveness of aspiration as an initial treatment for spontaneous pneumothorax and to compare outcomes of patients managed by specialist respiratory physicians with those managed by general medical physicians.

\section{METHOD}

Records of all patients admitted with pneumothorax to our 400 bedded district general hospital between 1997 and 2002 were reviewed. Only patients who were symptomatic with a primary spontaneous pneumothorax of greater than $2 \mathrm{~cm}$ rim were included in the study. The patients were divided into two groups depending on whether they had been managed by a general or a respiratory physician. Patients were allocated to a general or respiratory physician's care solely on the basis of the day the patient attended hospital. Outcomes measured were: (a) use of aspiration as an initial treatment, (b) need for intercostal drain insertion, (c) complications of intercostal draindefined as tube displaced sufficient to require new drain insertion, severe surgical emphysema requiring intervention, or infection, and (d) length of hospital stay. It was also recorded whether advice was given to patients and recorded in the notes about flying and steps to take if symptoms recurred after discharge. Aspiration was undertaken using a 14F plastic cannula inserted into the chest in the second intercostal space in the mid-clavicular line. The introducer needle was withdrawn and the cannula attached to a $50 \mathrm{ml}$ luer lock syringe using a three way tap. Air was expelled until no more was present, the patient became uncomfortable or a maximum of 2.5 litres was withdrawn. Intercostal drains were inserted between the fourth and sixth intercostal space and the anterior and posterior axillary lines with the fifth

\begin{tabular}{lll} 
Table 1 & Patient characteristics \\
\hline & $\begin{array}{l}\text { Group 1 } \\
(\mathrm{n}=36)\end{array}$ & $\begin{array}{l}\text { Group 2 } \\
(\mathrm{n}=49)\end{array}$ \\
\hline & $24(67)$ & $42(86)$ \\
No $(\%)$ male & $40.6(18.0)$ & $38.9(21.4)$ \\
Mean (SD) age (years) & $8(22)$ & $12(25)$ \\
No $(\%)$ current or ex-smokers & $3(8)$ & $3(6)$ \\
No $(\%)$ with small pneumothorax & $28(78)$ & $38(78)$ \\
No $(\%)$ with large pneumothorax & $5(14)$ & $8(16)$ \\
No $(\%)$ with complete pneumothorax & 5 & \\
\hline
\end{tabular}

intercostal space in the mid-axillary line being the most commonly used. In two cases a drain was inserted in the second intercostal space in the mid-clavicular line. Drain sizes used varied between 16 and 24F gauge with size $20 \mathrm{~F}$ being the commonest. Data were analysed using $\chi^{2}$ test and MannWhitney U tests using SPSS.

\section{RESULTS}

During the study period 89 patients with primary spontaneous pneumothorax were identified of which records were available in 85 ( 66 male, 19 female). Thirty six were managed by respiratory physicians (group 1) and 49 by general physicians (group 2). There was no significant difference in age of patient or size of pneumothorax at presentation between the groups (table 1).

Results are summarised in table 2 . A significantly greater use of aspiration and a higher success rate of aspiration by respiratory physicians (group 1) was seen. Success of aspiration was defined as complete resolution of pneumothorax or reduction in size sufficient not to require any further intervention and to have relieved patients' symptoms. All patients who did not undergo aspiration or in whom aspiration was unsuccessful had an intercostal drain inserted. 
Table 2 Results of management by respiratory physicians (group 1) and general physicians (group 2)

\begin{tabular}{llll}
\hline & Group 1 & Group 2 & p Value \\
\hline No (\%) underwent aspiration & $29(81)$ & $23(47)$ & $<0.001$ \\
No $(\%)$ aspiration successful & $18(62)$ & $8(35)$ & $<0.001$ \\
No $(\%)$ with intercostal drain complications & $2(11)$ & $13(32)$ & 0.01 \\
No $(\%)$ with intercostal drain clamped & $2(11)$ & $7(17)$ & NS \\
No (\%) with outpatient follow up & $31(86)$ & $30(61)$ & $<0.01$ \\
No (\%) given advice on discharge about: & $8(22)$ & $4(8)$ & 0.05 \\
Symptom recurrence & $6(17)$ & $4(8)$ & NS \\
Flying & $5.6(3.8)$ & $9.5(6.8)$ & $<0.05$ \\
Mean (SD) length of stay (days) & $1.6(1.2)$ & $3.2(2.9)$ & NS \\
All patients & & & \\
Patients with successful aspiration & & & \\
\hline NS, not significant. & &
\end{tabular}

Those managed by respiratory physicians had fewer complications. Length of stay was significantly less in the group managed by respiratory physicians. When length of stay of those with successful aspiration was examined there was no significant difference between the two groups suggesting the greater and more successful use of aspiration by the respiratory physicians accounted for their shorter length of stays.

\section{DISCUSSION}

This is one of the largest studies to examine the role of aspiration in the treatment of spontaneous pneumothorax in medical inpatients. It is the first to directly compare outcomes of patients with pneumothorax managed by specialist respiratory and general physicians. It demonstrates that the use of simple aspiration as the initial treatment of choice in patients with pneumothorax reduces the need for intercostal drains and significantly shortens length of hospital stay independent of the initial size of the pneumothorax.

Previous studies have used length of stay as a primary endpoint. ${ }^{5-7}$ In a prospective randomised trial Harvey and Prescott found a significantly shorter mean length of stay of 3.2 days in the group treated with aspiration compared with 5.3 days in the group that had an intercostal drain. Andrivet $e t$ al found no difference in length of hospital stay mainly because there was a mean delay of 48 hours before aspiration was undertaken. In the study by Noppen et al only $52 \%$ of those that underwent manual aspiration required admission largely because they needed an intercostal tube for failed aspiration. Not surprisingly therefore the length of stay of the two groups did not differ. In our study when length of stay of only those who had undergone aspiration successfully was examined there was no significant difference between the two groups, suggesting it is the greater and more successful use of aspiration by the respiratory physicians that accounted for their reduced lengths of stay.

The success rate of aspiration of $63 \%$ in the respiratory group is similar to previous series $(45 \%-83 \%)$, even though all the aspirations were done by junior medical staff and not by research staff.$^{5-11}$ Respiratory physicians were more likely to follow up patients in the outpatient department and document that patients had been advised to return should they develop a recurrence of symptoms in accordance with British Thoracic Society guidelines. Documentation about advice given on flying was poor in both groups. ${ }^{12}$

This is the first study examining the management of spontaneous pneumothorax by specialists and generalists. It demonstrates better outcomes of care when patients are managed by respiratory physicians. A questionnaire survey of physicians in Wales showed a non-significant trend towards respiratory physicians following British Thoracic Society guidelines more than general physicians, but this is the first to show this happens in practice and that it affects patient outcomes. ${ }^{13}$
Studies of other respiratory diseases such as asthma and chronic obstructive pulmonary disease have shown similar benefits when patients are managed by specialist respiratory teams. ${ }^{14-16}$ There is also a growing body of literature from other medical disciplines demonstrating improved outcomes with specialist care. ${ }^{17-19}$ This study showed a higher complication rate of intercostal drains in patients managed by general physicians. There was a trend towards greater use of clamping by general physicians despite guidelines indicating this practice should not be followed due to its associated risks. ${ }^{2}$ Inserting intercostal drains is probably the commonest invasive respiratory procedure undertaken by junior medical staff, is often done unsupervised, yet can be associated with significant morbidity. ${ }^{20}$

The respiratory physicians' greater use and increased success of aspiration coupled with the reduced complication rate when intercostal drains were required led to significantly shorter length of stays. If these findings are confirmed in prospective multicentre studies the process of provision of respiratory healthcare in the United Kingdom may require review, in the way for example cardiologists are looking at temporary pacemaker insertion, ${ }^{21}$ to provide safer more cost effective management of pneumothorax.

\section{Authors' affiliations}

S Packham, P Jaiswal, Department of Respiratory Medicine, Queen Elizabeth the Queen Mother Hospital, Margate, Kent

\section{REFERENCES}

1 Morimoto T, Fukui T, Noguchi Y, et al. Optimal strategy for the first episode of primary spontaneous pneumothorax in young men. A decision analysis. J Gen Intern Med 2002;17:193-202.

2 Miller AC, Harvey JE. Guidelines for the management of spontaneous pneumothorax. BM 1993;307:114-16.

3 Schramel FM Sutedja TG Barber JC et al Cost effectiveness of video-assisted thoracoscopic surgery versus conservative treatment for first time or recurrent spontaneous pneumothorax. Eur Respir $J$ 1996;9:1821-5.

4 Baumann MH, Strange C, Heffner JE, et al. Management of spontaneous pneumothorax. An American College of Chest Physicians Delphi Consensus Statement. Chest 2001:119:590-602.

5 Harvey J, Prescott RJ. Simple aspiration versus intercostal tube drainage for spontaneous pneumothorax in patients with normal lungs. BM 1994;309: 1338-9.

6 Andrivet P, Djedaini K, Teboul J-L, et al. Spontaneous pneumothorax. Comparison of thoracic drainage vs immediate or delayed needle aspiration. Chest 1995;108:335-40.

7 Noppen $M$, Alexander $P$, Driesen $P$, et al. Manual aspiration versus chest tube drainage in first episodes of primary spontaneous pneumothorax: a multicenter, prospective, randomized pilot study. Am J Respir Crit Care Med 2002;165:1240-4.

8 Bevelaqua FA, Aranda C. Management of spontaneous pneumothorax with small catheter manual aspiration. Chest 1982;81:693-4.

9 Archer GJ, Hamilton AA, Upadhyay R, et al. Results of simple aspiration of pneumothoraces. BrJ Dis Chest 1985;79:177-82.

10 Jones SJ. A place for aspiration in the treatment of spontaneous pneumothorax. Thorax 1985;40:66-7 
11 Talbot-Stern J, Richardson H, Tomlanovich MC, et al. Catheter aspiration for simple pneumothorax. J Emerg Med 1986:4:437-42.

12 British Thoracic Society Standards of Care Committee. Managing patients with respiratory diseases planning air travel: BTS recommendations. Thorax 2002;57:289-304.

13 Yeoh JH, Ansari S, Campbell IA. Management of spontaneous pneumothorax-a Welsh survey. Postgrad Med J 2000;76:496-9.

14 Pearson MG, Ryland I, Harrison BDW. National audit of acute severe asthma in adults admitted to hospital. Quality in Health Care asthma in adults

15 Packham S. In-patient management of exacerbations of chronic obstructive pulmonary disease: is there a difference in care between respiratory and general physicians. Journal of Clinical Excellence 2000;2:119-22.
16 Roberts CM, Ryland I, Lowe D, et al. Audit of acute admissions of COPD: standards of care and management in the hospital setting. Eur Respir J 2001;17:343-9.

17 Schreiber TL, Elkhatib A, Grines CL, et al. Cardiologists versus internist management of patients with unstable angina: treatment patterns and outcomes. J Am Coll Cardiol 1995;26:577-82.

18 Masson J, Bramley PN, Herd K, et al. Upper gastrointestinal bleeding in an open access dedicated unit. J R Coll Phys Lond 1996;30:436-42.

19 Stevens PE, Tamimi NA, Al-Hasani MK, et al. Non-specialist management of acute renal failure. Q J Med 2001;94:533-40.

20 Hyde J, Sykes T, Graham TR. Reducing morbidity from chest drains. BM 1997;314:914-15.

21 Murphy JJ. Problems with temporary cardiac pacing. BM $2001 \cdot 323 \cdot 527$

\section{Clinical Evidence-Call for contributors}

Clinical Evidence is a regularly updated evidence based journal available worldwide both as a paper version and on the internet. Clinical Evidence needs to recruit a number of new contributors. Contributors are health care professionals or epidemiologists with experience in evidence based medicine and the ability to write in a concise and structured way.

Currently, we are interested in finding contributors with an interest in the following clinical areas:

Altitude sickness; Autism; Basal cell carcinoma; Breast feeding; Burns; Carbon monoxide poisoning; Cervical cancer; Chronic renal failure; Cystic fibrosis; Ectopic pregnancy; Emphysema; Grief/bereavement; Halitosis; Hodgkins disease; Infectious mononucleosis (glandular fever); Jet lag; Kidney stones; Malignant melanoma (metastatic); Mesothelioma; Myeloma; Ovarian cyst; Pancreatitis (acute); Pancreatitis (chronic); Polycystic ovaries; Polymyalgia rheumatica; Post-partum haemorrhage; Pulmonary embolism; Recurrent miscarriage; Repetitive strain injury; Scoliosis; Seasonal affective disorder; Squint; Systemic lupus erythematosus; Testicular cancer; Uterine prolapse; Varicocele; Viral meningitis; Vitiligo

However, we are always looking for others, so do not let this list discourage you.

Being a contributor involves:

- Appraising the results of literature searches (performed by our Information Specialists) to identify high quality evidence for inclusion in the journal.

- Writing to a highly structured template (about 2000-3000 words), using evidence from selected studies, within 6-8 weeks of receiving the literature search results.

- Working with Clinical Evidence Editors to ensure that the text meets rigorous epidemiological and style standards.

- Updating the text every eight months to incorporate new evidence.

- Expanding the topic to include new questions once every 12-18 months.

If you would like to become a contributor for Clinical Evidence or require more information about what this involves please send your contact details and a copy of your CV, clearly stating the clinical area you are interested in, to Claire Folkes (cfolkes@bmigroup.com).

\section{Call for peer reviewers}

Clinical Evidence also needs to recruit a number of new peer reviewers specifically with an interest in the clinical areas stated above, and also others related to general practice. Peer reviewers are health care professionals or epidemiologists with experience in evidence based medicine. As a peer reviewer you would be asked for your views on the clinical relevance, validity and accessibility of specific topics within the journal, and their usefulness to the intended audience (international generalists and health care professionals, possibly with limited statistical knowledge). Topics are usually 2000-3000 words in length and we would ask you to review between 2-5 topics per year. The peer review process takes place throughout the year, and our turnaround time for each review is ideally 10-14 days.

If you are interested in becoming a peer reviewer for Clinical Evidence, please complete the peer review questionnaire at www.clinicalevidence.com or contact Claire Folkes (cfolkes@bmigroup.com). 